\title{
Determinantes socioeconômicos da criminalidade no estado do Paraná: uma análise espacial*
}

\author{
Socioeconomic determinants of crime in the state of Paraná: a spatial analysis
}

\author{
Miriã de Sousa Lucas, Marina Silva da Cunha e Kézia de Lucas Bondezan**
}

\begin{abstract}
Resumo: Este artigo tem como objetivo avaliar a dependência espacial da criminalidade nos municípios do estado do Paraná no ano de 2015, bem como seus possíveis determinantes. A taxa de homicídios por agressões é utilizada como proxy para a criminalidade e para identificar seus determinantes, são coletadas variáveis socioeconômicas e demográficas em que as fontes principais são os dados do IBGE, DATASUS e Ipardes. Para a análise empírica, utilizam-se técnicas de econometria espacial como a Análise Exploratória de Dados Espaciais (AEDE) e modelos econométricos espaciais. Os resultados encontrados indicam que a taxa de homicídios nos municípios paranaenses não é distribuída aleatoriamente no espaço, sendo possível identificar clusters do tipo Alto-Alto na região metropolitana de Curitiba. Por meio dos modelos de defasagem do termo de erro (SEM) e modelo Durbin espacial do erro (SDEM) identificou-se que a taxa de homicídios sofre influência das seguintes variáveis: densidade demográfica, coeficiente de Gini, taxa de desemprego, proporção de jovens do sexo masculino, proporção de lares cujas mães são chefes de família e proporção de estudantes com atraso escolar.
\end{abstract}

Palavras-chave: Econometria espacial; Paraná; Taxa de Homicídios

\begin{abstract}
The aim of this paper is to analyze the spatial dependence of crime in the municipalities of the state of Paraná in the year of 2015, as well as its possible determinants. The rate of homicides for aggression is used as a proxy for crime and to identify its determinants. Socioeconomic and demographic variables were collected, being their main sources IBGE, DATASUS and Ipardes data. For the empirical analysis, techniques of spatial econometrics such as the Exploratory Analysis of Spatial Data (AEDE) and spatial econometric models are used. The results indicate that the homicide rate in Paraná municipalities is not randomly distributed in space, and it is possible to identify clusters of the High-High type in the metropolitan region of Curitiba. By means of the error term (SEM) and Durbin Spatial Error Model (SDEM) models, the homicide rate is influenced by the following variables: demographic density, Gini coefficient,

\footnotetext{
* Submissão: 02/08/2019; aprovação: 08/12/2019. DOI: 10.5380/re.v41i75.68314.

** Respectivamente, doutoranda em Teoria Econômica pela Programa de Pós Graduação em Ciências Econômicas da Universidade Estadual de Maringá (UEM). E-mail: miriaslucas@gmail.com. Professora titular do Departamento de Ciências Econômicas da Universidade Estadual de Maringá (UEM). E-mail: mscunha@uem.br. ORCID: 0000-0001-9122-3944. Professora adjunta do Departamento de Ciências Econômicas da Universidade Estadual de Maringá (UEM).E-mail: klbondezan@uem.br.
} 
unemployment rate, proportion of young men, proportion of households whose mothers are heads of household, and proportion of students with school delays.

Keywords: Homicide rate; Paraná; Spatial econometrics

JEL Code: R1; R23 


\section{Introdução}

A criminalidade é um grave problema social e econômico que afeta diretamente a vida dos cidadãos gerando perda de bem-estar, de produtividade, de renda familiar, comprometendo a segurança do indivíduo e gerando custos econômicos para o governo, que precisa alocar cada vez mais recursos para políticas de combate à violência no país. No Brasil, esse problema tem crescido de forma expressiva nos últimos anos. Dados do Sistema de Informação sobre Mortalidade do Departamento de Informática do SUS (SIM-DATASUS) apontam que no ano 2000 foram registrados 45.360 homicídios $^{1}$; já em 2015 esse número aumentou para 58.138, um aumento de 28,17\% ao longo de 16 anos, o que evidencia o quão preocupante é essa temática.

O aumento nas taxas de crime, os elevados custos a elas associados e a crescente importância dada ao assunto têm levado os governos e a sociedade civil a encarar o problema da criminalidade como um dos mais sérios obstáculos ao desenvolvimento econômico e social do país. O maior desafio está em formular e implementar políticas que permitam prevenir e reduzir o crime e a violência. Diante disso, o número de pesquisas nessa temática vem ganhando espaço, sendo que muitas delas procuram compreender e mensurar quais são os determinantes da criminalidade e assim colaborar com os formuladores de políticas públicas a fim de fornecer subsídios para traçar estratégias que visem a redução desses indicadores (FAJNZYLBER; ARAUJO JR., 2001).

Uma das principais teorias para explicação dos atos criminosos é atrelar essa prática às condições sociais do indivíduo, como desemprego, má qualidade de vida, má distribuição de renda e escolaridade. Esses condicionantes são apontados como os principais determinantes para a criminalidade. Contudo, conforme apontado por Sass, Porsse e Silva (2016) e Olini et al. (2018), mesmo com a melhora de indicadores sociais em regiões do Brasil, como o Índice de Desenvolvimento Humano Municipal (IDHM) e o Índice de GINI, pelos quais o primeiro mostra o desenvolvimento dos municípios e o segundo retrata a desigualdade de renda, as taxas de crimes, principalmente as taxas de homicídios, continuam a crescer.

\footnotetext{
${ }^{1} \mathrm{Na}$ base SIM-DATASUS foi utilizado os dados da $10^{\circ}$ versão da Classificação Internacional de Doenças (CID 10): óbitos por causas externas - agressões, que correspondem aos códigos X85 até Y09.
} 
No Paraná, por exemplo, foco da análise desse trabalho, o IDHM e o Índice de GINI passaram de 0,65 e 0,60, respectivamente, em 2000, para 0,75 e 0,53 em 2010, confirmando assim a melhoria no desenvolvimento humano e redução da desigualdade de renda no estado. Destaca-se que em 2010 o Paraná representava o segundo estado do Brasil com o menor índice de Gini $(0,53)$, ficando atrás apenas de Santa Catarina (0,49). Além disso, entre 2000 e 2010, o estado apresentou o segundo maior crescimento no IDHM (acréscimo de 0,27 no indicador), ocupando a quinta posição no ranking dos estados. Contudo, ainda assim, a taxa de homicídios aumentou, chegando a 25,63 óbitos por 100 mil habitantes no ano de 2015 contra 18,27 óbitos por 100 mil habitantes no ano de 2000 (BRASIL, 2019).

Nesse contexto, considerando que a desigualdade de renda e demais variáveis socioeconômicas selecionadas para o presente estudo podem influenciar as taxas de homicídios, pergunta-se: qual a relação entre essas variáveis e a criminalidade (taxa de homicídios) nos municípios paranaenses no ano de 2015 , considerando um possível comportamento espacial das taxas de criminalidade? Assim, o presente artigo busca encontrar padrões espaciais das taxas de homicídios nos municípios paranaenses e identificar seus determinantes.

Para atingir esse objetivo, utiliza-se dados coletados dos 399 municípios paranaenses e aplicam-se técnicas de econometria espacial, como a Análise Exploratória de Dados Espaciais (AEDE) e os métodos econométricos espaciais, tais como: modelo de defasagem da variável dependente (SAR), modelo de defasagem do termo de erro (SEM) e modelo Durbin espacial do erro (SDEM); em conjunto com os dados disponibilizados pelo IBGE, Ipardes e DATASUS.

O artigo está organizado, além da introdução, em mais 4 seções. A segunda seção apresenta uma discussão teórica e empírica sobre os determinantes do crime e da existência de dependência espacial desse fenômeno em diferentes regiões do país. Na terceira seção é apresentado o procedimento metodológico utilizado na análise. A quarta seção discorre sobre os resultados da pesquisa e, por fim, na quinta seção apresentam-se as considerações finais.

\section{Referencial teórico}

A pesquisa em economia do crime passou a ser evidenciada após a publicação de um estudo realizado por Becker (1968), que relacionou a 
criminalidade com variáveis econômicas. Até então a criminalidade era alvo de investigações sociológicas. $\mathrm{O}$ autor relatou em seu estudo que, embora ilegal, o crime é visto como uma alternativa de atividade econômica. Sendo assim, a pessoa só cometerá um crime se a utilidade que ela espera por esse ato exceder a utilidade que teria alocando seu tempo em atividades legais. Assim, o ato criminoso decorre de uma avaliação racional acerca dos custos e benefícios esperados pelo crime em comparação aos resultados obtidos caso o indivíduo venha a despender seu tempo no mercado de trabalho, em uma ocupação legal.

Becker (1968) também apontou que a escolaridade tem impacto sobre a criminalidade, ou seja, o nível escolar altera o custo de oportunidade da atividade ilícita, pois, quanto mais qualificado for um indivíduo, melhores oportunidades no mercado de trabalho ele obtém, auferindo maiores salários e melhores empregos, o que aumenta o custo de cometer um crime. Outro fator importante a ser avaliado é que a punição pode ser mais custosa para indivíduos com maior escolaridade, visto que, quando preso, o tempo fora do mercado de trabalho pode custar graves consequências ao criminoso quando retornar.

A literatura empírica relaciona alguns determinantes da criminalidade, como o trabalho de Andrade e Lisboa (2000), que utilizou modelos logit para analisar o comportamento da taxa de homicídios na população masculina e sua relação com variáveis econômicas nos estados de Minas Gerais, Rio de Janeiro e São Paulo, entre os anos de 1981 e 1997. Os principais resultados obtidos indicaram que um aumento do salário real e uma queda da desigualdade de renda reduzem a taxa de homicídios, com impacto relativamente maior sobre a coorte de homens de 15 a 40 anos de idade. Nesse sentido, as evidências sugerem que homens jovens são mais propensos a se envolverem no crime, sendo que a falta de oportunidade no mercado de trabalho legal pode ser decisiva na sua opção de atuar, ou não, na criminalidade (SARAIVA; CONCEIÇÃO; FRANÇA, 2017).

Por sua vez, Gutierrez et al. (2004) buscaram esclarecer os determinantes da criminalidade no Brasil. Utilizando modelo econométrico de dados em painel para diferentes estados brasileiros entre os anos de 1981 e 1995, os autores observaram que a desigualdade de renda desempenha um papel fundamental na determinação da criminalidade. Além disso, taxas de desemprego e o grau de urbanização estão relacionados de modo diretamente proporcional com a criminalidade. 
A importância de avaliar o impacto da educação sobre a criminalidade foi atestada por Teixeira (2011), que buscou verificar a relação da criminalidade com a educação, mensurando o impacto da taxa de abandono escolar dos alunos da primeira série do segundo grau, defasada em um período, sobre a criminalidade no Brasil, para os anos entre 2001 e 2005 . Utilizando dados em painel, foi possível observar que existe relação significativa entre a taxa de abandono escolar defasada e as taxas de homicídios nos estados brasileiros, ou seja, após abandonar a escola, no início do ensino médio, há maior probabilidade de um jovem ingressar no "mundo do crime".

Mendonça e Sachsida (2012) estimaram os efeitos de políticas de repressão sobre as taxas de homicídios no Brasil utilizando modelo de dados em painel. Para isso, os autores dividiram políticas de repressão em duas partes: incapacitação, que visa avaliar as taxas de encarceramento no país; e detenção, que compreende uma avaliação dos efeitos de um aumento no policiamento (civil e militar) como determinante da redução do crime no país. Em sua análise, realizada para os municípios brasileiros entre 2001 e 2009, o autor concluiu que prender mais bandidos e aumentar o número de policiais civis e militares reduz a taxa de homicídios no Brasil, independente do que ocorra com outras variáveis socioeconômicas.

Os autores supracitados constataram que existe um impacto inercial da taxa de homicídios, sendo que um aumento de $10 \%$ na taxa de homicídios em um ano implica um acréscimo de $9 \%$ da referida taxa no ano seguinte. Além disso, quando analisaram as variáveis socioeconômicas, foi possível observar que uma redução na desigualdade de renda não garante redução da taxa de homicídios, já uma elevação da população jovem masculina pode implicar um aumento nas taxas de homicídios. Por fim, não foi possível constatar que uma queda na taxa de desemprego causa redução nas taxas de homicídios (MENDONÇA; SACHSIDA, 2012).

Becker e Kassouf (2017) procuraram verificar se o aumento dos investimentos em educação contribuem para redução nas taxas de homicídios no Brasil. Em um estudo para os 26 estados brasileiros e o Distrito Federal, entre os anos de 2001 a 2009 e utilizando análise de dados em painel, foi possível constatar que, se os gastos com educação aumentarem em 10\%, a taxa de homicídios se reduz em $1 \%$ no período seguinte. Verificou-se também que um aumento de $10 \%$ nos gastos com segurança pública implica uma redução de $7,8 \%$ na taxa de homicídios. No caso do índice de Gini, um aumento de $10 \%$ nesse indicador pode 
acarretar um aumento na taxa de homicídios de 7,8\% no curto prazo e 5,8\% no longo prazo. Foi possível constatar que a variável desemprego afeta os custos de oportunidade do crime, contudo, a relação não é imediata, visto que a decisão do indivíduo de participar de atividades ilícitas não ocorre logo após a demissão. Por fim, a variável urbanização também apresentou relação positiva e significativa com a taxa de homicídios no Brasil.

Considerando que violência apresenta uma distribuição geográfica não randômica no espaço, ou seja, regiões que estão geograficamente próximas de comunidades violentas tendem a apresentar altos graus de violência, vários estudos têm introduzido em suas análises componentes espaciais para compreender os determinantes da criminalidade em diversas localidades (GRIFFITH; CHAVEZ, 2004).

Oliveira (2008) empregou técnicas de econometria espacial para analisar os determinantes da criminalidade no estado do Rio Grande do Sul para o ano de 2000. O autor estimou modelos econométricos para três variáveis dependentes: crime contra a pessoa, crime contra o patrimônio e taxa de homicídios. Os resultados obtidos apontaram que a estrutura familiar (dada pelo percentual de famílias cuja única fonte de renda é originária de indivíduos do sexo feminino) e a ineficiência do ensino no estado afetam positivamente a criminalidade.

Ainda nesse contexto, Gaulez e Maciel (2015), ao analisar os determinantes da criminalidade para o estado de São Paulo no ano de 2011, utilizaram como proxy para a criminalidade a variável "crimes contra o patrimônio" (que inclui todos os tipos de furtos e roubos). Utilizando técnicas de econometria espacial, constataram que o crime contra o patrimônio ocorre em regiões onde o retorno esperado é maior, ou seja, densidade demográfica, grau de urbanização e maior nível de renda afetam positivamente a criminalidade, sendo que o grau de urbanização apresenta maior impacto na criminalidade, segundo o qual um aumento de $1 \%$ dessa variável eleva em $12,4 \%$ a criminalidade.

Sass, Porsse e Silva (2016) investigaram os determinantes da criminalidade para os municípios do estado do Paraná no ano de 2012 através de técnicas de econometria espacial. Os resultados obtidos apontaram que o grau de urbanização e a taxa de pobreza elevam a taxa de homicídios nos municípios do estado. Além disso, ao estimar modelos espaciais com efeito local, o modelo sugeriu que o aumento do efetivo policial teria efeito sobre os crimes dessa região, o que não foi 
possível observar nos modelos estimados globalmente. Com isso, foi possível concluir que políticas de segurança pública devem ser implementadas avaliando as características de cada região para que venham a surtir o efeito desejado.

A análise espacial acerca da criminalidade também foi estudada por Moreira e Fochezatto (2017), que procuraram identificar os fatores capazes de explicar a dinâmica da violência e o padrão de organização espacial nos municípios do estado da Bahia no ano de 2014. Em sua análise, os autores criaram um Índice de Criminalidade dos Municípios Baiano (IcrimeBA), composto pelos principais delitos ocorridos, a fim de obter a totalidade de ocorrências. Os principais resultados apontaram a existência de um processo de difusão da criminalidade entre os municípios e as regiões vizinhas; além disso, foi possível constatar também que municípios com maior densidade demográfica apresentam maiores taxas de criminalidade.

Já Plassa, Paschoalino e Santos (2017) analisaram a distribuição espacial e os determinantes socioeconômicos da taxa de homicídio no Nordeste brasileiro para o ano de 2014. Como procedimento metodológico os autores utilizaram a Análise Exploratória de Dados Espaciais (AEDE) e modelos econométricos espaciais. Os resultados da análise apontaram que a desigualdade de renda exerce a maior influência nas taxas de homicídios nos municípios da região Nordeste. Além disso, foi possível observar que a densidade populacional, grau de urbanização e taxa de analfabetismo também apresentaram significância estatística para explicar a taxa de homicídios na região.

Por fim, Olini et al. (2018) buscaram analisar a relação espacial entre as taxas de homicídio e desigualdade de renda no Estado de Mato Grosso nos anos de 2000 e 2010. Utilizando técnicas de econometria espacial, os autores constataram influência dos municípios vizinhos na taxa de homicídios, além disso, observou-se também uma relação positiva entre criminalidade e desigualdade de renda, visto que houve redução do Índice de Gini (evidenciando menor concentração de renda) e dos homicídios no período analisado. Nas estimações econométricas, os autores encontraram relação positiva entre a criminalidade e variáveis como: pobreza, densidade demográfica, mães chefes de família e proporção da população jovem.

Diante do exposto, constata-se a importância de estudos com enfoque geográfico para compreender os determinantes da criminalidade nas mais diversas localidades. Analisar a perspectiva espacial da evolução do crime é fundamental 
para identificar as regiões mais afetadas e promover subsídios para a elaboração de políticas públicas que visem modificar a presente realidade.

Apesar disso, uma consideração importante que deve ser destacada é que os estudos apresentados nessa revisão de literatura tratam da criminalidade e os fatores socioeconômicos utilizando uma abordagem com dados secundários, do tipo ecológico, como destacado por Tittle, Villemez e Smith (1978), ou seja, trata dos condicionantes de um fenômeno de comportamento individual (criminalidade) com dados agregados. Esse tipo de análise pode levar a resultados bem diferentes dos que seriam encontrados caso fosse utilizada uma pesquisa com dados primários. Esse fato foi observado pelos autores ao mostrarem que a relação entre criminalidade e fatores socioeconômicos apresentou redução ao longo do tempo.

Quando se utiliza dados do tipo ecológico (secundários), o mesmo comportamento pode não ser verificado quanto utilizados dados individuais (primários). Entretanto, ainda que essas limitações sejam impostas, os resultados empíricos apresentados nessa revisão de literatura apontam que essa associação tem encontrado suporte nos estudos recentes, o que justifica a utilização desse tipo de dados.

\section{Dados e metodologia}

\subsection{Dados}

A variável que o presente artigo busca explicar é a taxa de homicídio nos municípios paranaenses, que foi utilizada como uma proxy da violência observada nessa região. A justificativa para o uso dessa variável é que, além de haver uma elevada taxa de sub-registro em outros tipos de crimes, não há dados suficientes que permitam uma análise deste estudo com outra mensuração para a criminalidade (SANTOS; FILHO, 2011; SASS; PORSSE; SILVA, 2016).

Para amenizar algum efeito externo aleatório que tenha impactado a taxa de homicídio em determinado ano, é considerada a média aritmética dessas taxas referentes aos anos 2013, 2014 e 2015. Diante da incompatibilidade cronológica de produções estatísticas, uma vez que os censos brasileiros são realizados a cada período de dez anos, as variáveis: taxa de desemprego, coeficiente de Gini e proporção de mães chefes de família; referem-se à última divulgação censitária, ou seja, ao ano de 2010. 
A utilização das variáveis do último Censo Demográfico para a análise da criminalidade violenta registrada entre os anos de 2013 e 2015 é justificada pelo fato de que a criminalidade pode ser entendida como um processo que se desenvolve num cenário socioeconômico que necessita de um intervalo de tempo para ser construído (BATELLA; DINIZ, 2010). As variáveis densidade demográfica e a taxa de atraso escolar foram obtidas através do Ipardes para o ano de 2015 e a proporção de jovens do sexo masculino (entre 15 e 29 anos) foi estimada com base nos dados do IBGE, também para o ano de 2015.

A base dos dados de óbitos foi coletada do Sistema de Informação sobre Mortalidade, Data SUS (SIM-DATASUS), em que foram utilizados os dados da $10^{\mathrm{a}}$ versão da classificação Internacional de Doenças (CID-10): óbitos por causas externas - agressões, que correspondem aos códigos X85 até Y09. Em seguida foi realizado o cálculo da taxa de homicídio por 100 mil habitantes utilizando estimativas intercensitárias disponibilizadas pelo Instituto Brasileiro de Geografia e Estatística (IBGE). As variáveis utilizadas neste artigo, suas definições, fonte de dados e sinal esperado são apresentadas na tabela 1 . 
Tabela 1 - Definição das variáveis e estatísticas descritivas

\begin{tabular}{|c|c|c|c|}
\hline Variável & Definição & Fonte & $\begin{array}{c}\text { Sinal } \\
\text { esperado }\end{array}$ \\
\hline Taxa média de homicídios ${ }^{1}$ & $\begin{array}{l}\text { Taxa média de homicídios por } \\
100 \text { mil/ habitantes dos anos de } \\
2013 \text { a } 2015 .\end{array}$ & $\begin{array}{l}\text { SIM- } \\
\text { DATASUS }\end{array}$ & \\
\hline Coeficiente de Gini & $\begin{array}{l}\text { Índice de Gini da renda } \\
\text { domiciliar per capita segundo } \\
\text { município em que } 0 \text { (zero) } \\
\text { denota não desigualdade e } 1 \\
\text { (um) que existe desigualdade } \\
\text { extrema. }\end{array}$ & IBGE & + \\
\hline Desemprego & $\begin{array}{l}\text { Proporção da população } \\
\text { residente economicamente ativa } \\
\text { de } 18 \text { anos ou mais que se } \\
\text { encontra sem trabalho na } \\
\text { semana de referência. }\end{array}$ & IBGE & + \\
\hline Homens de 15 a 29 anos & $\begin{array}{l}\text { Proporção de indivíduos homens } \\
\text { entre } 15 \text { a } 29 \text { anos em relação à } \\
\text { população total. }\end{array}$ & IBGE & + \\
\hline Atraso escolar & $\begin{array}{l}\text { Proporção de alunos, em cada } \\
\text { série / ano, do ensino } \\
\text { fundamental, com idade } \\
\text { superior à idade recomendada, } \\
\text { que é de } 14 \text { anos (anos iniciais } \\
\text { de } 6 \text { a } 10 \text { anos e anos finais de } \\
11 \text { a } 14 \text { anos de idade). }\end{array}$ & IPARDES & + \\
\hline Mães chefes de família & $\begin{array}{l}\text { Proporção de mães chefes de } \\
\text { família, sem ensino fundamental } \\
\text { completo e com pelo menos um } \\
\text { filho menor de } 15 \text { anos de idade }\end{array}$ & IBGE & + \\
\hline Densidade demográfica & $\begin{array}{l}\text { Relação entre a população e a } \\
\text { área geográfica municipal. }\end{array}$ & IPARDES & + \\
\hline
\end{tabular}

Fonte: elaboração própria.

As variáveis explicativas foram selecionadas conforme estudos realizados por vários autores sobre os determinantes da criminalidade em diversas regiões do país. Uma vez que as taxas de violência e criminalidade não são distribuídas aleatoriamente no espaço, mas concentram-se em áreas com maior grau de urbanização, pode-se constatar que sua distribuição está diretamente relacionada às estruturas físicas e sociais dos ambientes (GRIFFITH; CHAVEZ, 2004). 
Diante disso, utilizando como base a teoria da desorganização social ${ }^{2}$, as variáveis explicativas foram selecionadas para representar características estruturais e socioeconômicas que afetam as taxas de criminalidade em uma determinada localidade.

As variáveis coeficiente de Gini e taxa de desemprego são frequentemente introduzidas em análises que buscam compreender os determinantes da criminalidade, visto que várias teorias sugerem que há efeitos da desigualdade de renda sobre a criminalidade. A teoria da desorganização social, por exemplo, enfatiza que a pobreza e a desigualdade seriam responsáveis pela insegurança e pela instabilidade social e, assim, levariam a um aumento nas taxas de crimes (WANG; ARNOLD, 2008). Além disso, apoiando-se nas reflexões de BriceñoLeón (2002), que afirmam que o empobrecimento e a desigualdade são responsáveis pelo incremento da criminalidade, o índice de Gini representa uma importante medida de concentração de riquezas e, portanto, uma variável relevante para captar a incidência criminal.

A variável "mães chefes de família" foi incluída na regressão para captar o impacto da estrutura familiar na criminalidade, uma vez que a família desempenha um papel fundamental no desenvolvimento dos indivíduos. Assim como destacado por Oliveira (2008), quando as famílias são chefiadas apenas por mulheres, essas podem enfrentar várias adversidades, que vão desde a redução da renda familiar, visto que a mulher pode ser a única provedora financeira do lar, até problemas para a criação dos filhos.

Ainda nesse contexto, Olini et al. ( 2018) argumentam em sua pesquisa que, ao se dedicar ao trabalho, principalmente exercendo a função de chefe de família, a mulher tem menos tempo dedicado aos filhos, o que pode contribuir para que eles sejam expostos à maior probabilidade de praticarem crimes. Apesar de essa argumentação ser utilizada em diversos trabalhos nessa área, Menezes et al. (2013) enfatizam que não há comprovação científica para esse fato; assim se faz

\footnotetext{
${ }^{2}$ A teoria da desorganização social refere-se a uma abordagem sistêmica cujo enfoque gira em torno das comunidades locais, sendo estas entendidas como um complexo sistema de redes de associações formais e informais, de relações de amizade, parentesco e outras que, de alguma forma, contribuam para o processo de socialização e aculturação do indivíduo. Essas relações seriam condicionadas por fatores estruturais, como status econômico, heterogeneidade étnica e mobilidade residencial. Assim, a criminalidade surge como consequência de efeitos indesejáveis presentes na organização dessas relações comunitárias e de vizinhança (CERQUEIRA; LOBÃO, 2004).
} 
necessário que se pense em alternativas, tal como a utilizada na presente pesquisa, para captar a questão da estrutura familiar.

A densidade demográfica foi inserida na análise com o objetivo de captar o efeito urbano sobre as taxas de homicídios. Segundo Glaeser e Sacerdote (1999), menores probabilidades de prisão e menor probabilidade de reconhecimento do criminoso são características da vida urbana e estão entre os fatores que ligam o efeito urbano às taxas de crimes. Para testar o efeito da educação sobre os homicídios, considerou-se a taxa de atraso escolar, mensurada pela distorção idade/série dos alunos matriculados no ensino fundamental. Menores taxas de analfabetismo podem reduzir crimes, haja vista que a punição pode ser mais custosa para indivíduos com maior escolaridade (BECKER, 1968). Por fim, o percentual de jovens do sexo masculino na população foi empregado como uma variável de controle pois, conforme apontado pelo Mapa da Violência de 2016, uma das características marcantes dos homicídios por armas de fogo no Brasil é sua predominância na população jovem masculina entre 15 e 29 anos.

A amostra compreende 399 municípios pertencentes ao estado do Paraná. É importante destacar que para as especificações econométricas foi aplicado o logaritmo das variáveis para que a análise dos coeficientes encontrados seja feita através de termos percentuais e assim facilitar a compreensão dos resultados obtidos.

\subsection{Metodologia}

Para identificar os determinantes da criminalidade nos municípios do estado do Paraná e analisar sua distribuição geográfica, são utilizadas nesta pesquisa técnicas de econometria espacial. Inicialmente é realizada a Análise Exploratória de Dados Espaciais (AEDE), uma coleção de técnicas utilizadas para identificar padrões espaciais nos dados. A partir da existência de autocorrelação espacial, são utilizados modelos econométricos que empregam componentes espaciais na análise.

\subsubsection{Análise Exploratória de Dados Espaciais (AEDE)}

Conforme Almeida (2012), a Análise Exploratória de Dados Espaciais (AEDE) é uma coleção de técnicas para análise estatística de informação geográfica e tem por objetivo descrever e visualizar distribuições espaciais, identificar observações discrepantes no espaço, descobrir padrões de associação 
espacial e sugerir clusters espaciais. Para implementá-la, é necessário primeiramente definir uma matriz de ponderação espacial ou matriz de pesos espaciais $(W)$, que representa o grau de conexão entre as regiões segundo algum critério de proximidade. Dessa forma, para cada ponto do espaço, é definido um conjunto de vizinhança relevante que, potencialmente, interage com ele (ANSELIN, 1999).

Após determinar a matriz de pesos espaciais, é necessário verificar se as variáveis são distribuídas aleatoriamente ou se são autocorrelacionadas no espaço. Para isso, utiliza-se a estatística $I$ de Moran global, um coeficiente de associação linear que algebricamente é dado por:

$$
I=\frac{n}{S_{0}} \frac{\sum_{i} \sum_{j} w_{i j} z_{i} z_{j}}{\sum_{i=1}^{n} z_{i}^{2}}
$$

em que: $n$ refere-se ao número de unidades espaciais, $z$ denota os valores da variável de interesse padronizada; $W z$ representa os valores médios da variável de interesse padronizada nos vizinhos, definidos segundo uma matriz de ponderação espacial $W$ e $S_{0}$ significa a soma de todos os elementos das matrizes espaciais $W$. (ALMEIDA, 2012).

O valor esperado do $I$ de Moran, sob a hipótese nula de não haver autocorrelação espacial, é de $-[1 /(n-1)]$. Assim, valores próximos de zero indicam a ausência de um padrão espacial dos dados, apontando a inexistência de autocorrelação. Se o valor calculado for maior que o valor esperado, há indícios de autocorrelação espacial positiva, ou seja, se a variável analisada apresentar valor alto (baixo) em um local, apresentará valor alto (baixo) da mesma variável nas localizações vizinhas. Por sua vez, se o $I$ de Moran calculado obtiver valor menor que o esperado, há indícios de autocorrelação negativa (ALMEIDA, 2012).

Uma abordagem alternativa para visualizar a autocorrelação espacial é baseada no diagrama de dispersão de Moran; contudo, a autocorrelação global pode camuflar padrões locais de associação espacial estatisticamente significativa (como clusters ou outliers); sendo assim, um dos indicadores utilizados na literatura capaz de capturar esses efeitos é o I de Moran local, denominado por Anselin (1995) indicador LISA (Local Indicator of Spatial Association). Segundo o autor, um "Local Indicator of Spatial Association (LISA)" será qualquer estatística que satisfaça a dois critérios: a) possuir para cada observação uma indicação de clusters espaciais significantes de valores similares em torno da 
observação e b) o somatório dos LISAs para todas as regiões é proporcional ao indicador de autocorrelação espacial global.

O coeficiente $I_{i}$ de Moran local faz uma decomposição do indicador global de autocorrelação na contribuição local de cada observação em quatro categorias (AA, BB, AB e BA), cada uma individualmente correspondendo a um quadrante no diagrama de dispersão de Moran. O coeficiente de $I_{i}$ de Moran local, para uma variável y padronizada, observada na região $i, z_{i}$, pode ser expresso como:

$$
I_{i}=z_{i} \sum_{j=1}^{j} w_{i j} z_{j}
$$

Para que $I_{i}$ seja um indicador LISA é necessário obter a soma dos indicadores locais do $I$ de Moran, conforme o critério acima citado. Sendo assim, para cada observação é computado um $I_{i}$, obtendo $n$ computações da estatística $I_{i}$ e os seus respectivos níveis de significância, sendo que, uma forma eficiente de apresentar esse conjunto de estatísticas é mapeá-las obtendo então o mapa de cluster LISA.

O mapa de cluster LISA combina a informação do diagrama de dispersão de Moran e a informação do mapa de significância das medidas de associação local $I_{i}$; ; além disso, o mapa ilustra a classificação das quatro categorias de associação espaciais estatisticamente significativas (ALMEIDA, 2012).

\subsubsection{Modelos econométricos espaciais}

Após a Análise Exploratória dos Dados Espaciais (AEDE), caso se confirme a presença de dependência espacial, os modelos propostos para avaliar os determinantes da criminalidade no estado do Paraná devem incorporar os componentes espaciais. No presente trabalho foram estimados o Modelo de Defasagem Espacial (SAR), que adiciona a defasagem da variável dependente na regressão, Modelo de Defasagem Espacial (SEM), que considera a defasagem do termo de erro na regressão e, por fim, o modelo Durbin Espacial do erro (SDEM), que contempla defasagens das variáveis independentes e do termo de erro.

Para a escolha do modelo mais adequado, o primeiro passo é estimar o modelo clássico de regressão linear por meio do método dos Mínimos Quadrados Ordinários (MQO). Através desse, realiza-se o teste de $I$ de Moran dos resíduos. Esse teste é feito com o intuito de encontrar uma possível existência de autocorrelação espacial. Se não for possível rejeitar a hipótese nula do teste, de que 
os resíduos são distribuídos aleatoriamente no espaço, não existe a confirmação da existência de autocorrelação espacial e, portanto, opta-se pelo modelo MQO:

$$
y=\alpha+\beta X+\varepsilon
$$

em que $y$ é um vetor $n \times 1$ de observações sobre a variável dependente, $X$ é uma matriz $n \times k$ de observações sobre as variáveis explicativas exógenas (mais a constante) com um vetor associado $k \mathrm{x} 1$ de coeficiente de regressão $\beta$ e $\varepsilon$ é um vetor $n \times 1$ de termos de erro aleatório, com média zero e variância constante.

Contudo, se a hipótese nula do teste de I de Moran for rejeitada, confirmase a presença de autocorrelação espacial e, portanto, é necessário encontrar o formato que a autocorrelação assume. Para isso, aplica-se o teste do Multiplicador de Lagrange, em que ML $\rho$ analisa a defasagem espacial da variável dependente, e tem como hipótese nula $\rho=0$ e ML $\lambda$ analisa a autocorrelação espacial no termo de erro, e tem como hipótese nula $\lambda=0$. Caso ambos os testes não sejam significativos, são mantidos os resultados do modelo estimado por MQO, caso contrário, segue-se para o próximo passo.

Se somente ML $\rho$ for significativo, o modelo mais adequado é o de Defasagem Espacial (SAR), que assume o seguinte formato:

$$
y=\rho W y+X \beta+\varepsilon
$$

em que $W y$ é a variável dependente defasada pela matriz de pesos espaciais, $\rho$ é o coeficiente autorregressivo espacial, que mede a influência média dos vizinhos sobre a observação no vetor $y$ indicando a proporção da variação total em $y$ explicada pela dependência espacial, $X$ é uma matriz de variáveis explicativas exógenas, $\beta$ são os coeficientes da regressão e $\varepsilon$ é o erro aleatório.

No entanto, se somente ML $\lambda$ for significativo, o modelo apropriado é o de Erro Espacial (SEM), que pode ser especificado da seguinte forma funcional:

$$
y=X \beta+\xi
$$

em que $X$ é uma matriz de variáveis explicativas exógenas, $\beta$ são os coeficientes da regressão, $\xi=\lambda W \xi+\varepsilon$, no qual o coeficiente $\lambda$ é o parâmetro do erro autorregressivo espacial que acompanha a defasagem $W \xi$ mais o erro. 
Contudo, se ambos forem significativos, é necessário verificar as extensões do teste, ou seja, o Multiplicador de Lagrange robusto, sendo eles: ML* $\rho$ e ML* $\lambda$; o mais significativo indica o modelo mais apropriado (ALMEIDA, 2012).

Para fins de comparação, é estimado também o Modelo Durbin Espacial do erro (SDEM). A justificativa para a estimação desse modelo é o fato de possuir um alcance global, dado pelo multiplicador espacial da variável dependente, e um alcance local, dado pelas defasagens espaciais do termo de erro:

$$
y=X \beta+W X_{\tau}+\xi
$$

em que $X$ é uma matriz de variáveis explicativas exógenas, $\beta$ são os coeficientes da regressão, $W X_{\tau}$ representa as defasagens espaciais para as variáveis explicativas exógenas, onde $\tau$ é um vetor $(\mathrm{k}-1$ por 1$)$ e $\xi=\lambda W \xi+\varepsilon$, representa o termo de erro, no qual o coeficiente $\lambda$ é o parâmetro do erro autorregressivo espacial que acompanha a defasagem $W \xi$.

\section{Resultados e discussões}

\subsection{Análise descritiva}

A Tabela 2 reporta a estatística descritiva das variáveis selecionadas, correspondente aos 399 municípios do estado do Paraná. Observa-se que a média anual da taxa de homicídios por 100 mil habitantes foi de 18,85, com coeficiente de variação de $74,78 \%$, indicando que há disparidades da criminalidade nas regiões analisadas. Destaca-se que os municípios $^{3}$ de Janiópolis (80,30/100 mil habitantes), Espigão Alto do Iguaçu (79,83/ 100 mil habitantes) e Almirante Tamandaré $(65,73 / 100$ mil habitantes) apresentaram as maiores taxas de homicídios no período analisado (2013 a 2015).

\footnotetext{
${ }^{3}$ Tabela A1, no apêndice do trabalho.
} 
Tabela 2 - Análise descritiva dos dados utilizados na pesquisa

\begin{tabular}{lccccc}
\hline Variável & Média & $\begin{array}{c}\text { Desvio } \\
\text { padrão }\end{array}$ & $\begin{array}{c}\text { Coeficiente } \\
\text { de variação } \\
(\boldsymbol{\%})\end{array}$ & Mínimo & Máximo \\
\hline Taxa média de homicídios & 18,853 & 14,098 & 74,780 & 0,000 & 80,304 \\
Coeficiente de Gini & 0,466 & 0,057 & 12,263 & 0,330 & 0,660 \\
Desemprego & 0,041 & 0,017 & 40,690 & 0,004 & 0,101 \\
Homens de 15 a 29 anos & 0,123 & 0,117 & 9,505 & 0,084 & 0,157 \\
Atraso escolar & 0,136 & 0,048 & 35,196 & 0,047 & 0,333 \\
Mães chefes de família & 0,152 & 0,070 & 46,002 & 0,019 & 0,522 \\
Densidade demográfica & 18,061 & 88,382 & 4,893 & 0,312 & $1.421,445$ \\
\hline
\end{tabular}

Fonte: elaboração própria.

Ao analisar as variáveis explicativas selecionadas, destacam-se: proporção de mães chefes de família, desemprego e atraso escolar, que apresentaram coeficiente de variação expressivo, correspondendo a 46,00\%, 40,69\% e 35,20\%, respectivamente. Essas disparidades evidenciam que diversos municípios do estado apresentam grande vulnerabilidade socioeconômica e isso pode ajudar a explicar o porquê de as taxas de homicídios apresentarem valores mais elevadas em determinadas regiões.

\subsection{Distribuição das taxas de homicídio}

A distribuição espacial das taxas de homicídios por agressões nos municípios pertencentes aos estados do Paraná pode ser observada através da Figura 1. O que se pretende descobrir é se os dados referentes às taxas de homicídios são distribuídos aleatoriamente no espaço ou seguem um padrão espacial sistemático. 
Figura 1 - Distribuição das taxas de homicídio no Estado do Paraná: 2013-2015

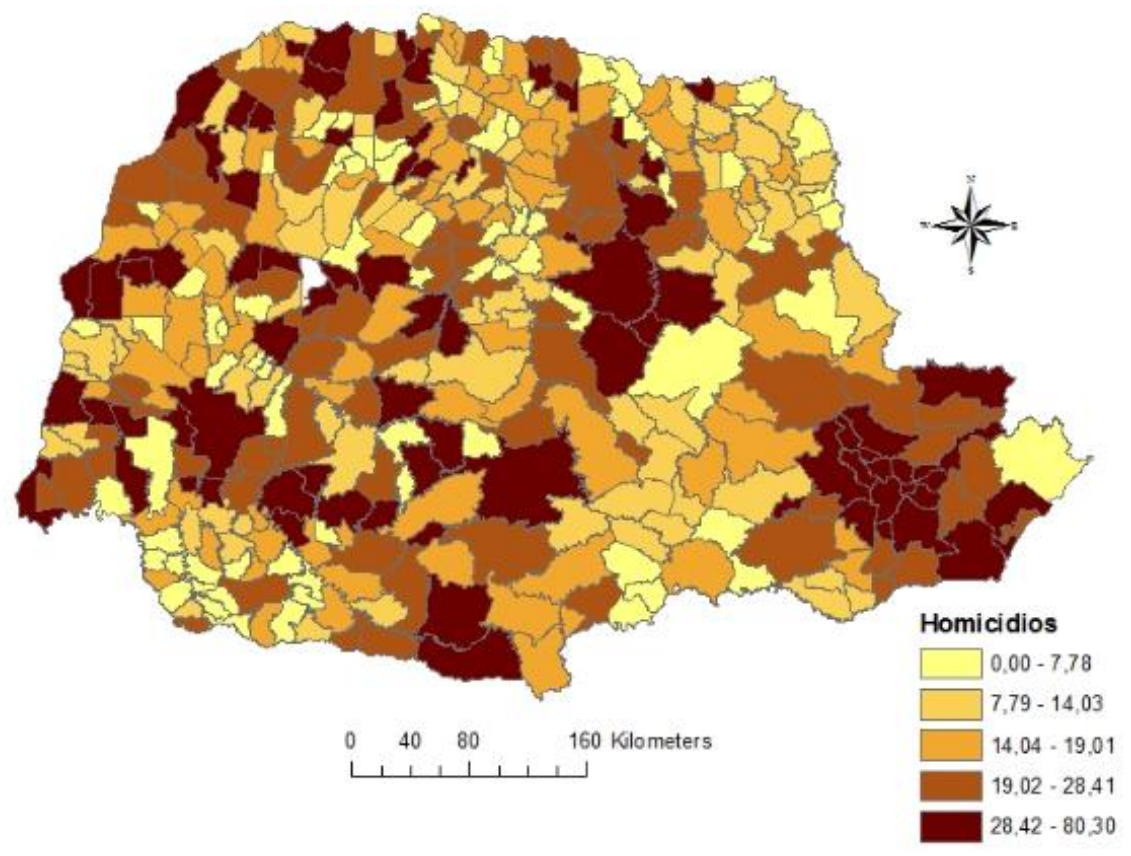

Fonte: elaboração própria a partir do software Arcgis.

Nos pontos mais escuros do mapa encontram-se as regiões com maiores taxas de homicídio por 100 mil habitantes; por sua vez, nos pontos mais claros são encontrados os municípios com as menores taxas. De fato, a impressão é que, na região metropolitana de Curitiba, encontram-se os municípios com maiores taxas de homicídios, sugerindo a existência de clusters espaciais. Todavia, conforme destacado por Almeida (2012), é necessário usar alguma estatística de teste que permite averiguar a aleatoriedade da distribuição espacial da variável sob estudo de forma global. A possível constatação desse fato é apresentada nas próximas seções.

\subsection{Teste de autocorrelação global e local}

Esta seção tem como objetivo analisar a existência de uma possível dependência espacial da taxa de homicídio nos municípios paranaenses. Para isso, o trabalho faz uso dos testes de autocorrelação global e local, disponibilizados pela Análise Exploratória de Dados Espaciais (AEDE). A primeira etapa da AEDE consiste em testar se os dados estão distribuídos aleatoriamente no espaço ou apresentam autocorrelação espacial. Para isso, calcula-se a estatística $I$ de Moran 
com diferentes matrizes de pesos espaciais, a saber: rainha, torre, 5 vizinhos mais próximos (K5) e 8 vizinhos mais próximos (K8).

$\mathrm{O} I$ de Moran tem um valor esperado $\mathrm{E}(I)$ de -[1/n-1]. Pela fórmula nota-se que $\mathrm{E}(I)$ para os 399 municípios paranaenses é de -0,0025. Assim, valores acima de $\mathrm{E}(I)$ indicam autocorrelação positiva. A Tabela 3 apresenta as estatísticas Globais $I$ de Moran, onde é possível observar que os valores excedem o $\mathrm{E}(I)$ e são significativos a $1 \%$. Isso implica que municípios que possuem altas (baixas) taxas de homicídios são circundados por regiões que também apresentam altas (baixas) taxas, isto é, há similaridade entre valores de uma determinada região e seus vizinhos. Outra observação feita é que os dados não foram sensíveis às diferentes convenções de matrizes de pesos espaciais utilizadas. Os valores, em geral, foram bem próximos e todos apresentaram significância estatística.

Tabela 3 - Estatísticas Globais I de Moran para a variável correspondente à taxa de homicídio

\begin{tabular}{lccc}
\hline \multicolumn{1}{c}{ Convenção } & $\boldsymbol{I}$ & p-valor & z-valor \\
\hline Rainha & 0,241 & 0,001 & 7,784 \\
Torre & 0,241 & 0,001 & 7,755 \\
K5 & 0,259 & 0,001 & 8,648 \\
K8 & 0,241 & 0,001 & 9,918 \\
\hline
\end{tabular}

Fonte: elaboração própria.

Após a constatação da significância da estatística global, procura-se identificar padrões de associação linear espacial localizada através do $I$ de Moran local (Ii). Sendo assim, para cada observação é computado um $I_{i}$. Dessa forma, obtém-se $n$ computações da estatística $I_{i}$ e os seus respectivos níveis de significância, sendo que, uma maneira eficiente de apresentar esse conjunto de estatísticas é mapeá-las obtendo então o mapa de cluster LISA, que combina a informação do diagrama de dispersão de Moran e a informação do mapa de significância das medidas de associação local $I_{i}$ (ALMEIDA, 2012). A Figura 2 apresenta o diagrama de dispersão de Moran e o mapa de cluster LISA para a taxa de homicídios por agressões no estado do Paraná. 


\section{Figura 2 - Diagrama de dispersão de Moran e mapa de clusters LISA para as taxas de homicídio por agressões no Estado do Paraná: 2013-2015}

(a) Diagrama de dispersão de Moran

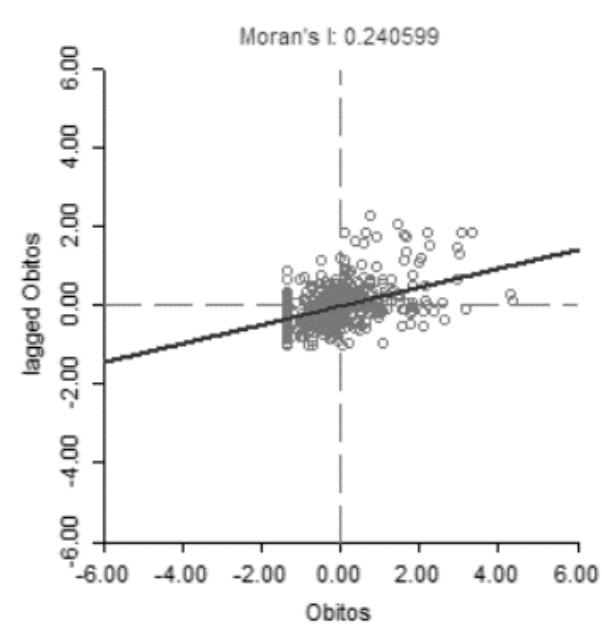

(b) Mapa de cluster LISA

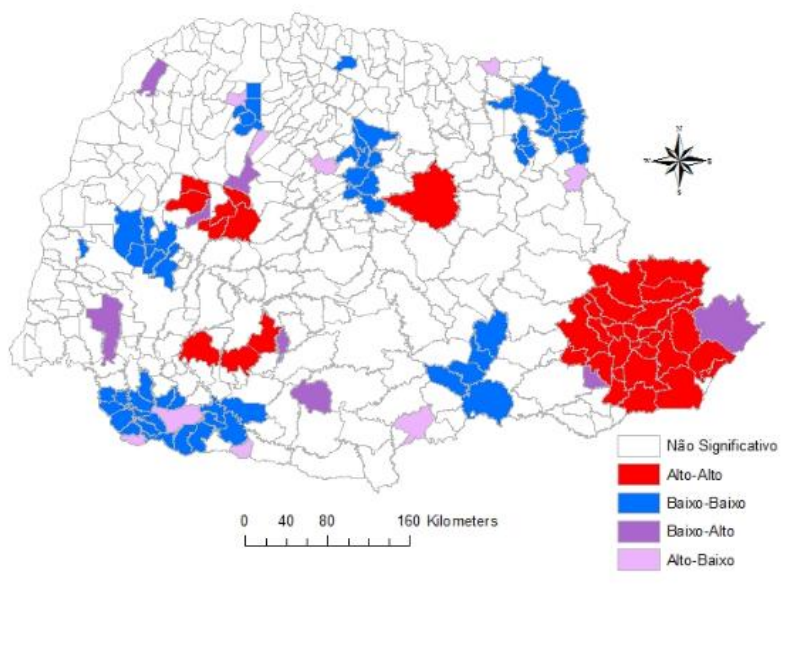

Fonte: elaboração própria.

Nota$^{1}$ : diagrama de dispersão de Moran elaborado a partir do software Geoda.

Nota²: mapa de cluster LISA elaborado a partir do software Arqgis.

O diagrama de dispersão de Moran apresenta quatro categorias: alto-alto (AA), baixo-baixo (BB), baixo-alto (BA) e alto-baixo (AB). O agrupamento AA apresenta as unidades que possuem elevado indicador da taxa de criminalidade e a média dos vizinhos também é alta, já as aglomerações BB refere-se aos municípios com baixa taxa de criminalidade e a média das unidades vizinhas está na mesma situação. Os clusters BA representam regiões com baixa taxa de criminalidade e o indicador médio dos municípios vizinhos é alto e as unidades caracterizadas como AB representam o grupo de municípios com elevado indicador de criminalidade, mas a média das unidades contíguas é baixa. Para facilitar a visualização geográfica das informações apresentadas no diagrama de dispersão de Moran, realiza-se o mapa de cluster LISA, em que a estatística local I de Moran é aplicada a partir da matriz de pesos espaciais $\mathrm{K} 8$, e as outras convenções apresentaram resultados similares.

Nas áreas representadas pela cor vermelha estão as aglomerações de municípios com altas taxas de homicídios e que são cercadas por municípios com as mesmas características (Alto-Alto). A cor azul identifica o grupo de associação espacial cujas regiões mostram valores baixos da taxa de homicídios rodeadas por 
municípios também com baixas taxas dessa variável (Baixo-Baixo). Os agrupamentos espaciais do tipo Alto-Baixo e Baixo-Alto apresentam-se dispersos pelo mapa.

É importante destacar que o maior agrupamento observado, Alto-Alto, é composto por alguns municípios da Região Metropolitana de Curitiba (RMC). Enquanto a capital paranaense apresenta bons indicadores socioeconômicos, como, por exemplo, baixa taxa de pobreza e alto índice de desenvolvimento humano, diversos municípios que estão ao seu redor enfrentam situação oposta. Sendo assim, essa disparidade socioeconômica pode ser um dos fatores que levam à concentração do crime nessa região (SASS; PORSSE; SILVA, 2016).

$\mathrm{Na}$ análise multivariada, a variável de interesse (taxa de homicídios por agressões) é relacionada com diversas variáveis selecionadas para o modelo que representam características socioeconômicas e demográficas dos municípios paranaenses, a saber: proporção da população desempregada, índice de Gini, proporção de alunos com atraso escolar, densidade demográfica, proporção de mães chefes de família e proporção de homens jovens entre 15 e 29 anos. A Figura 3 apresenta o diagrama de dispersão de Moran bivariado, em que o indicador taxa de homicídios por agressões está plotado no eixo horizontal e as demais variáveis são representadas no eixo vertical.

No quadrante AA estão concentradas as unidades que apresentam alto valor da taxa de homicídios e das variáveis selecionadas para a análise. Já o quadrante BA engloba as unidades com baixo valor da taxa de homicídios e alto valor das demais variáveis. O quadrante BB é concernente às unidades com baixo valor da taxa de homicídios e as variáveis selecionadas também apresentam baixos valores; por fim, no quadrante $\mathrm{AB}$, são concentrados os municípios onde a taxa de homicídio é alta e as variáveis selecionadas apresentam baixos valores (Figura 3). 
Figura 3 - Diagrama de dispersão de Moran bivariado para a taxa de homicídios no Paraná e demais variáveis
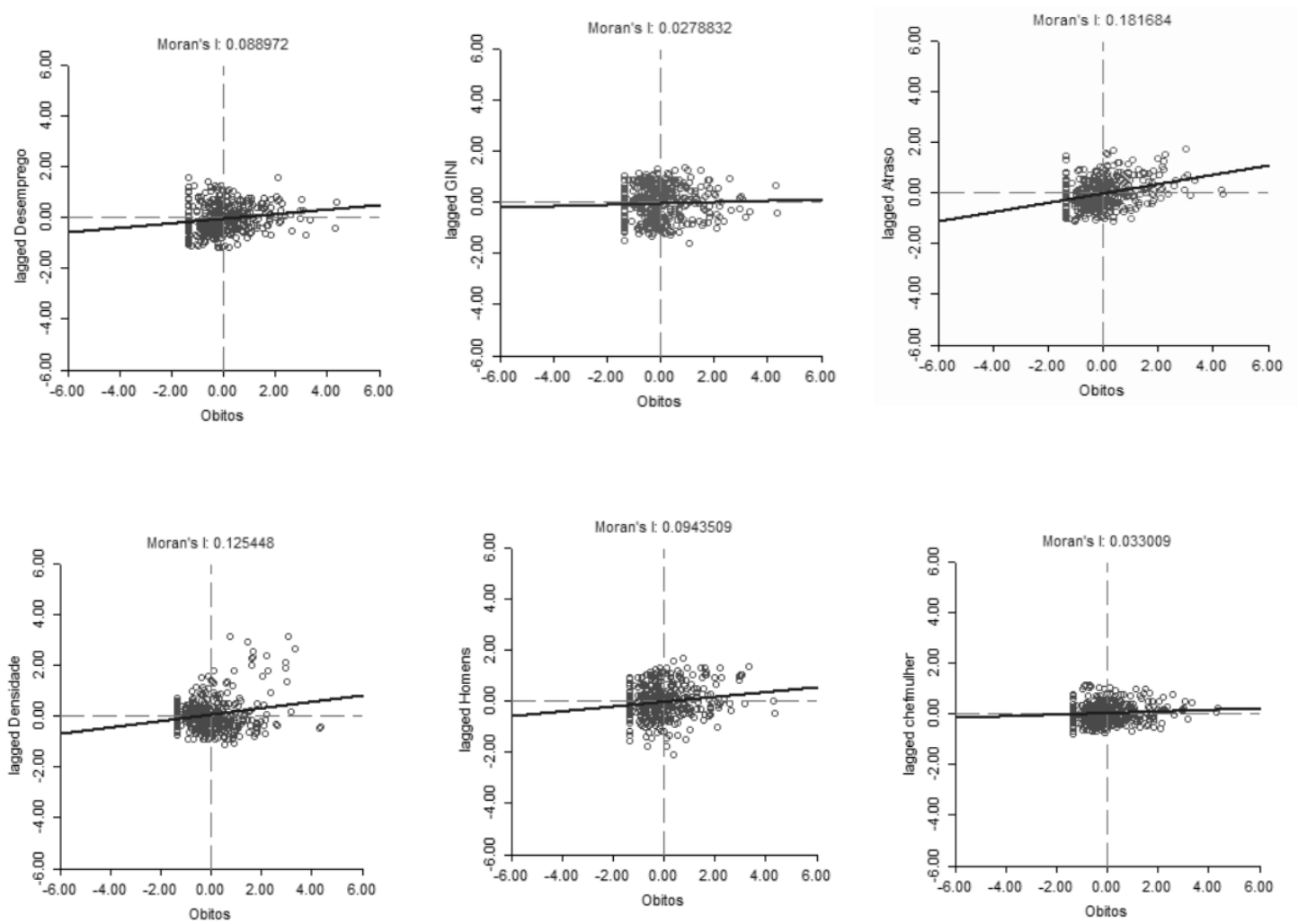

Fonte: elaboração própria a partir do software Geoda.

Pelos diagramas de dispersão de Moran bivariados apresentados no Figura 3 é possível visualizar que a criminalidade está relacionada positivamente com as variáveis selecionadas. Os resultados são reforçados pela inclinação positiva da reta de regressão; nesse sentido, é possível afirmar que as unidades municipais com elevada taxa de homicídios por agressões estão cercadas por municípios vizinhos com altos indicadores nas variáveis: taxa de desemprego, índice de Gini, taxa de atraso escolar, densidade demográfica, homens jovens entre 15 e 29 anos e população em extrema pobreza.

\subsection{Resultados dos modelos econométricos espaciais}

Após a Análise Exploratória dos dados, são apresentadas e discutidas nessa seção as estimativas dos modelos econométricos espaciais. Para tanto, é analisado como os fatores socioeconômicos e demográficos explicam as taxas de homicídios 
por 100 mil habitantes nos municípios do estado do Paraná para 2015. Primeiramente se faz necessário identificar uma possível autocorrelação espacial bem como seu formato; para isso, realiza-se o teste $I$ de Moran com os resíduos da regressão estimada pelo método dos Mínimos Quadrados Ordinários (MQO).

A Tabela 4 reporta o diagnóstico para a autocorrelação espacial. É possível observar que o teste $I$ de Moran indica que há autocorrelação espacial nos erros para as quatro convenções de matrizes utilizadas (rainha, torre, K5 e K8); esse resultado aponta que os modelos econométricos espaciais apresentam melhores ajustes aos dados. Ao analisar as convenções de matrizes espaciais, observa-se que a matriz de oito vizinhos mais próximos (K8) apresentou resultados mais significativos em relação às demais, e por esse motivo essa é a matriz adotada na estimação do modelo. Através dos ML $\rho$ e ML $\lambda$, ambos estatisticamente significativos a 1\%, não foi possível identificar o modelo espacial a ser estimado; sendo assim, observa-se os resultados da extensão do teste Multiplicador de Lagrange, ou seja, os testes Multiplicador de Lagrange robusto. O teste ML $\lambda$ robusto é mais significativo que o teste $\mathrm{ML} \rho$ robusto, indicando que a autocorreção espacial assume a forma no termo de erro.

Tabela 4 - Diagnóstico para autocorrelação espacial

\begin{tabular}{lcccc}
\hline \multicolumn{1}{c}{ Diagnóstico } & Rainha & Torre & K5 & K8 \\
\hline I de Moran dos erros & $4,324 * * *$ & $4,311^{* * *}$ & $3,731^{* * *}$ & $4,631^{* * *}$ \\
& $(0,000)$ & $(0,000)$ & $(0,000)$ & $(0,000)$ \\
ML (Defasagem) & $9,977 * * *$ & $9,986^{* * *}$ & $9,305^{* * *}$ & $11,433^{* * *}$ \\
& $(0,002)$ & $(0,002)$ & $(0,002)$ & $(0,001)$ \\
ML (Defasagem) robusto & 0,003 & 0,004 & 0,023 & 0,402 \\
& $(0,954)$ & $(0,951)$ & $(0,879)$ & $(0,526)$ \\
ML (Erro) & $16,573^{* *}$ & $16,476^{* * *}$ & $12,052^{* * *}$ & $18,138^{* * *}$ \\
& $(0,000)$ & $(0,000)$ & $(0,001)$ & $(0,000)$ \\
ML (Erro) robusto & $6,599 * * *$ & $6,495 * * *$ & $2,770 * *$ & $7,107 * * *$ \\
& $(0,010)$ & $(0,011)$ & $(0,096)$ & $(0,008)$ \\
\hline
\end{tabular}

Nota: entre parênteses está o valor da probabilidade. $* * * \mathrm{p} \leq 0,01, * * \mathrm{p} \leq 0,05$.

Fonte: elaboração própria.

Após a definição da matriz a ser adotada na análise, é preciso observar os resultados dos testes de diagnóstico para o modelo de regressão estimado por MQO. Há evidências de heteroscedasticidade, verificada através dos testes Breush-Pagan e Koenker-Bassett, cuja hipótese nula de homocedasticidade é 
rejeitada em ambos os testes. Além disso, constata-se também, através do teste Condition Number, que o modelo apresenta sinais de multicolinearidade, uma vez que o valor observado nesse teste foi superior a 30, apesar dessa evidência, o teste de multicolinearidade 4 indica que não há graves problemas de multicolinearidade no modelo. Além disso, o teste Jarque-Bera rejeitou a hipótese nula de normalidade nos resíduos, apontando que a regressão apresenta erros não normais ao nível de significância de $1 \%$, fato que pode causar problemas na estimação do modelo.

Tabela 5 - Diagnóstico da regressão estimada por OLS

\begin{tabular}{lccc}
\hline \multicolumn{1}{c}{ Teste } & DF & Valor & P-Valor \\
\hline Condition Number (Multicolinearidade) & - & 80,527 & - \\
Jarque Bera (Normalidade) & 2 & $95,358^{* * *}$ & $(0,000)$ \\
Breush-Pagan (Heterocedasticidade) & 6 & $53,186^{* * *}$ & $(0,000)$ \\
Koenker-Bassett (Heterocedasticidade) & 6 & $33,504^{* * *}$ & $(0,000)$ \\
\hline
\end{tabular}

Nota: $* * * \mathrm{p} \leq 0,01$.

Fonte: elaboração própria.

Os resultados do diagnóstico da regressão apresentados na Tabela 5 são necessários para a decisão de qual método utilizar na estimação dos modelos propostos. Devido à não normalidade dos erros, o Método da Máxima Verossimilhança (MV) não é o mais indicado na estimação; assim sendo, para o modelo SAR o método utilizado é o de Variáveis Instrumentais (estimador GS2SLS) e, para o modelo SEM e SDEM, é utilizado o Método Generalizado dos Momentos (GMM).

É importante destacar que todas as variáveis estão apresentadas em logaritmo. A transformação do logaritmo da variável dependente é calculada tomando o $\log$ de um mais a taxa de homicídio. Um é adicionado à taxa de homicídio para evitar tomar o log de zero (OSGOOD, 2000). As variáveis selecionadas como explicativas são as seguintes: densidade demográfica, coeficiente de Gini, proporção da população desempregada, proporção de estudantes do ensino fundamental com atraso escolar, proporção de homens jovens

\footnotetext{
${ }^{4}$ Para identificar se há multicolinearidade problemática entre os regressores do modelo, provocando efeitos nas estimativas dos coeficientes de regressão, optou-se por diagnosticá-la por meio do teste VIF (Variance Inflation Factor). Segundo Fávero et al. (2009), a interpretação indica que VIF acima de 10 e 1/VIF abaixo de 0,10 apresenta multicolinearidade problemática. Diante disso, após a realização do teste foi possível constatar que a multicolinearidade não é problemática no modelo (Tabela A2).
} 
entre 15 e 29 anos e proporção da população em que há possuem mães como chefes de família. Assim, as interpretações dos coeficientes serão dadas por suas elasticidades.

Os resultados dos modelos estimados são apresentados na Tabela 6. De modo geral, observa-se que os coeficientes seguem a mesma direção, com maior ou menor intensidade, dependendo do modelo abordado. Nota-se, a partir do teste Anselin-Kelejian, que o modelo SAR incorporou a autocorrelação espacial dos erros, rejeitando a hipótese nula (não autocorrelação espacial nos resíduos do modelo). Contudo, após o diagnóstico para a autocorrelação espacial (Tabela 5), constatou-se que o modelo SEM se mostrou mais ajustado aos dados, assim são comentados seus resultados, como também os resultados do modelo SDEM, que incorpora a defasagem das variáveis explicativas.

De acordo com os resultados do modelo SEM, que incorpora componentes de transbordamento espacial de alcance global, foi possível observar que existe uma relação espacial global positiva entre as taxas de homicídios por 100 mil habitantes no estado do Paraná e todas as variáveis selecionadas.

A variável coeficiente de Gini, com sinal positivo, sugere na análise que, quanto mais concentrada a renda nos municípios paranaenses, maior a criminalidade nessa região, ou seja, uma elevação de $1 \%$ desse indicador, aumenta em aproximadamente 0,97\% a taxa de homicídios nos municípios do estado. Resultado similar foi encontrado por Becker e Kassouf (2017) que, ao testar a influência da desigualdade social sobre a criminalidade para os estados brasileiros e o Distrito Federal no período 2001 a 2009, constataram que a desigualdade social, representada pelo índice de Gini, tem efeito positivo sobre a criminalidade.

Observou-se também que uma elevação de $1 \%$ na taxa de desemprego aumenta em $0,38 \%$ as taxas de homicídios nas regiões analisadas, corroborando os resultados encontrados por Gutierrez et al. (2004), numa análise para os estados brasileiros, e Plassa, Paschoalino e Santos (2017), em uma análise para a região Nordeste, onde constataram que a desigualdade de renda, taxas de desemprego e o grau de urbanização estão relacionados de forma positiva com a criminalidade. 
Tabela 6 - Resultados das Regressões

\begin{tabular}{|c|c|c|c|}
\hline Variáveis & SAR & SEM & SDEM \\
\hline Constante & $\begin{array}{c}11,005 * * * \\
(0,002)\end{array}$ & $\begin{array}{c}11,851 * * * \\
(0,000)\end{array}$ & $\begin{array}{c}6,926^{* * * *} \\
(0,005)\end{array}$ \\
\hline Densidade demográfica & $\begin{array}{c}0,091 * * * \\
(0,001)\end{array}$ & $\begin{array}{c}0,090 * * * \\
(0,001)\end{array}$ & $\begin{array}{c}0,092 * * * \\
(0,001)\end{array}$ \\
\hline Coeficiente de GINI & $\begin{array}{c}0,937 * * \\
(0,018)\end{array}$ & $\begin{array}{c}0,974 * * \\
(0,023)\end{array}$ & $\begin{array}{c}1,048 * * \\
(0,019)\end{array}$ \\
\hline Desemprego & $\begin{array}{c}0,408 * * * \\
(0,002)\end{array}$ & $\begin{array}{c}0,387 * * * \\
(0,000)\end{array}$ & $\begin{array}{c}0,323^{* * *} * \\
(0,006)\end{array}$ \\
\hline Atraso escolar & $\begin{array}{c}0,442 * * * \\
(0,004)\end{array}$ & $\begin{array}{c}0,340 * * \\
(0,018)\end{array}$ & $\begin{array}{c}0,317 * * \\
(0,029)\end{array}$ \\
\hline Homens de 15 a 29 anos & $\begin{array}{c}2,494 * * * \\
(0,000)\end{array}$ & $\begin{array}{c}2,942 * * * \\
(0,000)\end{array}$ & $\begin{array}{c}3,326 * * * \\
(0,000)\end{array}$ \\
\hline Mães chefes de família & $\begin{array}{c}0,215 * * \\
(0,036)\end{array}$ & $\begin{array}{l}0220 * * \\
(0,027)\end{array}$ & $\begin{array}{c}0,226 * * \\
(0,024)\end{array}$ \\
\hline$\rho$ & $\begin{array}{c}0,054 \\
(0,739)\end{array}$ & & \\
\hline$\lambda$ & & $\begin{array}{c}0,351 * * * \\
(0,000)\end{array}$ & $\begin{array}{c}0,322 * * * \\
(0,000)\end{array}$ \\
\hline W (Densidade demográfica) & & & $\begin{array}{c}0,010 \\
(0,900)\end{array}$ \\
\hline W (Coeficiente de GINI) & & & $\begin{array}{l}-0,149 \\
(0,859)\end{array}$ \\
\hline W (Taxa de desemprego) & & & $\begin{array}{l}-0,042 \\
(0,885)\end{array}$ \\
\hline W (Atraso escolar) & & & $\begin{array}{c}0,805 * * \\
(0,022)\end{array}$ \\
\hline W (Homens de 15 a 29 anos) & & & $\begin{array}{c}-3,163 * * * \\
(0,006)\end{array}$ \\
\hline W (Mães chefes de família) & & & $\begin{array}{c}0,226^{* *} \\
(0,024)\end{array}$ \\
\hline Pseudo $\mathrm{R}^{2}$ & 0,23 & 0,22 & 0,25 \\
\hline Anselin - Kalejian & 2,199 & - & - \\
\hline $\mathrm{N}^{\circ}$ de observações & 399 & 399 & 399 \\
\hline
\end{tabular}

Nota: entre parênteses está o valor da probabilidade. *** $\mathrm{p} \leq 0,01$, ** $\leq 0,05, * \leq 0,10$.

Fonte: elaboração própria.

Além disso, as variáveis densidade demográfica e percentual da população jovem masculina entre 15 e 29 anos também contribuem para um aumento das taxas de homicídios. As estimativas sugerem que $1 \%$ de aumento nessas variáveis, elevam as taxas de homicídio em $0,09 \%$ e 2,94\%, respectivamente. Assim, destaca-se que a variável que apresentou maior impacto sobre a criminalidade foi a proporção de jovens masculinos. Este resultado pode ser explicado pelo fato de 
que essa parcela da população, pela falta de oportunidades no mercado de trabalho legal, é mais propensa a se envolver com a criminalidade (SARAIVA; CONCEIÇÃO; FRANÇA, 2017).

O atraso escolar, com valor de 0,34 e estatisticamente significativo a 5\%, ressalta a importância da educação para a redução das taxas de violência nos municípios paranaenses. Esse resultado corrobora com aqueles encontrados por Oliveira (2008) e Teixeira (2011) ao avaliarem o impacto da educação sobre a criminalidade. Ambos os autores constataram uma relação significativa entre educação e criminalidade, sendo que o último encontrou evidências de que o abandono escolar provoca um aumento na criminalidade e o primeiro que a ineficiência no ensino contribui para aumentos nas taxas de criminalidade.

Por fim, a variável que representa o impacto da estrutura familiar na criminalidade apresenta também relação direta com a criminalidade, em que um aumento de $1 \%$ na proporção de famílias cujas mães são chefes de família elevam em aproximadamente $0,23 \%$ a criminalidade. Uma das explicações para esse resultado é que, embora as famílias monoparentais possam ser um fenômeno cada vez mais comum na sociedade, em média elas representam um fator de risco mais do que um fator de proteção com relação à criminalidade (OLIVEIRA, 2008), ou ainda, como argumentado por Olini et al. (2018), quando a mulher exerce a função de chefe de família, o tempo dedicado à educação dos filhos é menor e esse fato pode aumentar a probabilidade de eles entrarem no crime, afirmação essa que deve ser vista com cautela pois, com a inserção cada vez maior da mulher no mercado de trabalho, essa relação pode estar mudando.

Destaca-se que o coeficiente do erro autorregressivo espacial $(\lambda)$ apresentou significância estatística de $1 \%$ e sinal positivo $(0,32)$, indicando que os efeitos não captados pelo modelo apresentam autocorrelação espacial positiva. Sendo assim, altos (baixos) valores desses efeitos não modelados provocam choques de altos (baixos) valores na vizinhança.

Já no modelo SDEM (que incorpora componentes de transbordamento espacial de alcance global e local), observa-se que apenas a defasagem das variáveis Atraso escolar (W_Atraso escolar), Homens de 15 a 29 anos (W_Homens de 15 a 29 anos) e proporção da população em que a mãe é chefe da família (W_Mães chefes de família) apresentaram significância estatística. Assim, pode-se afirmar que, quanto maior o atraso escolar e maior a proporção 
da população em que as mães são chefes de família nos municípios vizinhos, maior será a taxa de homicídios nos municípios em análise. Já, a proporção de homens jovens nos municípios vizinhos, impactam negativamente a taxa de homicídio nos municípios analisados.

Esses resultados ressaltam a importância de se considerar o espaço geográfico em análises que procuram investigar os determinantes das tax as de homicídios para diferentes localidades, visto que, as características socioeconômicas e demográficas dos municípios podem impactar não somente na disseminação da criminalidade em seu território como também em municípios vizinhos.

\section{Considerações finais}

O objetivo do presente artigo foi analisar a distribuição espacial bem como os possíveis determinantes socioeconômicos e demográficos da taxa de homicídios por agressões nos municípios paranaenses, em 2015. Para tanto, utilizou-se a Análise Exploratória de Dados Espaciais (AEDE) e a especificação dos modelos econométricos espaciais, tais como: SAR, SEM e SDEM.

De acordo com os resultados, foi possível verificar a existência de dependência espacial da taxa de homicídios por agressões nos municípios paranaenses, sendo observadas aglomerações do tipo Alto-Alto na região metropolitana de Curitiba. Observou-se associação espacial positiva da densidade demográfica, coeficiente de Gini, taxa de desemprego, atraso escolar, homens jovens entre 15 e 29 anos e mães chefes de família sobre a taxa de homicídios por agressões nos municípios paranaenses.

Através desses resultados é possível afirmar que regiões mais urbanizadas, com elevado percentual da população jovem masculina, com grande nível de desigualdade econômica, com altas taxas de desemprego e atraso escolar, tendem a apresentar as maiores taxas de homicídios. Resultados esses que corroboram a literatura econômica sobre o tema através de evidencias empíricas, onde se aponta que a violência se destaca em grandes centros urbanos e que a educação e o desemprego impactam sobre os indicadores da criminalidade.

Foi possível observar também que a variável que capta a estrutura familiar, representada pela proporção da população em que as mães são chefes de família, 
também apresenta relação direta com a criminalidade. Visto que a família tem um papel fundamental para o suporte, especialmente financeiro, dos indivíduos, as alterações na estrutura da família podem impactar no desenvolvimento do indivíduo, levando-o a criminalidade.

Quando analisada a significância das defasagens espaciais das variáveis explicativas, observa-se a importância das características da vizinhança sobre as taxas de homicídios de determinado município. Reduzir o atraso escolar e estimular o mercado de trabalho na geração de empregos são algumas das principais ações a serem tomadas com o objetivo de diminuir a criminalidade nos municípios paranaenses, conforme apontado pelos modelos econométricos estimados.

Diante do exposto, este trabalho contribuiu para identificar alguns dos condicionantes do crime nos municípios paranaenses e procurou fornecer subsídios para que políticas de combate à criminalidade sejam discutidas a fim de reduzir as taxas de homicídios no estado. Portanto, destaca-se que políticas que tenham como foco a redução da desigualdade socioeconômica, a geração de emprego no mercado de trabalho legal, a ampliação de oferta de cursos profissionalizantes, que possam contribuir para a formação profissional do indivíduo e melhora na qualidade da educação, terão como contrapartida uma possível redução da taxa de homicídios por agressões na região analisada.

Por fim, como já apontado na revisão de literatura, estudos que abordem a temática sob o prisma individual, ou seja, com pesquisas de dados primários, podem contribuir para que os resultados apresentados nesse trabalho sejam confrontados e com isso seja possível comparar se a análise com dados agregados (ecológica) ou do tipo individual, podem de fato apontar resultados controversos, proposta essa que poderá ser retomada em trabalhos futuros com pesquisa primária apropriada para esse objetivo.

\section{Referências}

ALMEIDA, E. Econometria Espacial Aplicada. Alínea: Campinas, 2012.

ANSELIN, L. Spatial econometrics. A companion to theoretical econometrics, v. $310330,1999$.

ANSELIN, L. Spatial externalities, spatial multipliers and spatial econometrics. International Regional Science Review, v. 26, n. 3, 2003. 
ANDRADE, M. V., \& DE BARROS LISBOA, M. Desesperança de vida: homicídio em Minas Gerais, Rio de Janeiro e São Paulo: 1981 a 1997. In: Anais do IX Seminário sobre a Economia Mineira. Cedeplar, Universidade Federal de Minas Gerais, 2000.

BARBOSA, W. B.; ALVES, A. M. D. Análise espacial dos condicionantes da criminalidade violenta no estado de Minas Gerais. Sociedade \& Natureza, v. 22, n. $1,2010$.

BRASIL. IBGE. Instituto Brasileiro de Geografia e Estatística. Censo demográfico, v. 2010, 2010.

BRASIL. Ministério da Saúde. SIM-DATASUS. 2019. Disponível em: <http://datasus.saude.gov.br>. Acesso em: nov. 2019.

BRICEÑO-LEÓN, R. La nueva violencia urbana de América Latina. Sociologias. Porto Alegre, ano 4, n. 8, p. 34-51, 2002.

BECKER, G. S. Crime and punishment: an economic approach. Journal of Political Economy, v. 76, n. 1, p. 169-217, 1968.

BECKER, K. L.; KASSOUF, A. L. Uma análise do efeito dos gastos públicos em educação sobre a criminalidade no Brasil. Economia e Sociedade (UNICAMP), v. 26, p. 215-242, 2017.

CERQUEIRA, D.; LOBÃO, W. Determinantes da criminalidade: arcabouços teóricos e resultados empíricos. DADOS-Revista de ciências sociais, 47(2), 2004.

DOS SANTOS, M. J.; DOS SANTOS FILHO, J. I. Convergência das taxas de crimes no território brasileiro. EconomiA, 2011.

FAJNZYLBER, P.; ARAUJO JR, A. Violência e criminalidade. Microeconomia e sociedade no Brasil, p. 333-394, 2001.

FÁVERO, L. P. L.; BELFIORE, P. P., SILVA, F. L. D.; CHAN, B. L. Análise de dados: modelagem multivariada para tomada de decisões. São Paulo: Elsevier, 2009.

GAULEZ, M. P.; MACIEL, V. F. Determinantes da criminalidade no Estado de São Paulo: uma análise espacial de dados em cross-section. Anais do XLIII Encontro Nacional de Economia, 8, 2015. 
GLAESER, E. L.; SACERDOTE, B. Why is there more crime in cities? Journal of political economy, v. 107, n. 56, p. S225-S258, 1999.

GRIFFITH, E.; CHAVEZ, J. M. Communities, street guns and homicide trajectories in Chicago, 1980-1995: Merging methods for examining homicide trends across space and time. Criminology, v. 42, p. 941, 2004.

GUTIERREZ, M. B. S.; MENDONÇA, M. J. C.; SACHSIDA, A.; LOUREIRO, P. R. A. Inequality and criminality revisited: further evidence from Brazil. In: Anais do XXXII Encontro Nacional de Economia. ANPEC, Associação Nacional dos Centros de Pós-Graduação, 2004.

MENEZES, T.; SILVEIRA-NETO, R.; MONTEIRO, C.; RATTON, J. L. Spatial correlation between homicide rates and inequality: Evidence from urban neighborhoods. Economics Letters, v. 120, n. 1, p. 97-99, 2013.

MOREIRA, R. C.; FOCHEZATTO, A. Análise espacial da criminalidade no Estado da Bahia. Revista de Desenvolvimento Econômico, v. 3, n. 38, 2018.

OLINI, R. M.; DANIEL, L. P.; DALFOVO, W. C. T.; ORLANDINI, M; SHIKIDA, P. F. A. Homicídio e desigualdade de renda: uma análise espacial para o Estado de Mato Grosso em 2000 e 2010. Economic Analysis of Law Review, 9(3), 107-130, 2018.

OLIVEIRA, C. A. de. Análise espacial da criminalidade no Rio Grande do Sul. Revista de Economia, v. 34, n. 3 (ano 32), p. 35-60, 2008.

OSGOOD, D. W. Poisson-based regression analysis of aggregate crime rates. Journal of quantitative criminology, v. 16, n. 1, p. 21-43, 2000.

PARANÁ. Instituto Paranaense de Desenvolvimento Econômico e Social (IPARDES). Banco de Dados do Estado. Disponível em: <http://www.ipardes.pr.gov.br/imp/index.php>. Acesso em: jul. 2018.

PLASSA, W.; PASCHOALINO, P. T.; SANTOS, M. P. Determinantes socioeconômicos das taxas de homicídios no nordeste brasileiro: uma análise espacial. Anais do XIII Encontro de Economia Baiana, 2017.

SACHSIDA, A.; MENDONÇA, M. J. C. Evolução e determinantes da taxa de homicídios no Brasil (No. 1808). Texto para Discussão, Instituto de Pesquisa Econômica Aplicada (IPEA), 2013. 
SARAIVA, M. V.; CONCEIÇÃO, O. C.; FRANÇA, M. T. A. Os determinantes da criminalidade nos municípios gaúchos: evidências de um modelo econométrico espacial. Ensaios FEE, v. 38, n. 3, p. 521-552, 2017.

SASS, K. S.; PORSSE, A. A.; SILVA, E. R. H. Determinantes das taxas de crimes no Paraná: uma abordagem espacial. Revista Brasileira de Estudos Regionais e Urbanos, v. 10, p. 44-63, 2016.

TEIXEIRA, E. C. Dois ensaios acerca da relação entre criminalidade e educação - Tese apresentada para a obtenção do título de Doutor em Ciências - Área de concentração: Economia aplicada. Universidade de São Paulo, 2011.

TITTLE, C. R.; VILLEMEZ, W. J.; SMITH, D. A. The myth of social class and criminality: An empirical assessment of the empirical evidence. American sociological review, p. 643-656, 1978.

WANG, F.; ARNOLD, M. T. Localized income inequality, concentrated disadvantage and homicide. Applied Geography, v. 28, n. 4, p. 259-270, 2008.

WAISELFISZ, J. J. Mapa da violência 2016: homicídios por armas de fogo. Secretaria Nacional de Juventude, 2016. 


\section{Apêndice}

Tabela A1 - Dez municípios paranaenses com maior número de óbitos por 100 mil habitantes (2013-2015)

\begin{tabular}{clc}
\hline Ranking & Município & Óbitos/100 mil habitantes \\
\hline $1^{\circ}$ & Janiópolis & 80,30 \\
$2^{\circ}$ & Espigão Alto do Iguaçu & 79,83 \\
$3^{\circ}$ & Almirante Tamandaré & 65,73 \\
$4^{\circ}$ & Guaíra & 63,80 \\
$5^{\circ}$ & Piraquara & 61,95 \\
$6^{\circ}$ & Campina Grande do Sul & 61,12 \\
$7^{\circ}$ & Itaperuçu & 60,68 \\
$8^{\circ}$ & Fazenda Rio Grande & 60,32 \\
$9^{\circ}$ & Mauá da Serra & 55,96 \\
$10^{\circ}$ & Porto Barreiro & 55,53 \\
\hline
\end{tabular}

Fonte: elaboração própria com base nos dados do SIM-DATASUS.

Tabela A2 - Teste de multicolinearidade (modelo conjunto)

\begin{tabular}{lcc}
\hline \multicolumn{1}{c}{ Variável } & VIF & 1/VIF \\
\hline Coeficiente de Gini & 1,040 & 0,965 \\
Desemprego & 1,070 & 0,937 \\
Homens de 15 a 29 anos & 1,120 & 0,896 \\
Atraso escolar & 1,120 & 0,896 \\
Mães chefes de família & 1,010 & 0,986 \\
Densidade demográfica & 1,090 & 0,916 \\
\hline Média VIF & 1,07 & \\
\hline
\end{tabular}

Fonte: elaboração própria. 